\title{
PROPIEDAD, PRODUCCIÓN Y PAISAJE AGRARIOS EN POZUELO A FINALES DE LA EDAD MEDIA ${ }^{1}$
}

\author{
JULIÁN CLEMENTE RAMOS ${ }^{2}$
}

\begin{abstract}
Resumen: La economía agraria de Pozuelo, aldea de la tierra de Galisteo situada en la base de los relieves montañosos del Sistema Central, se caracteriza por la importancia de la producción no cerealícola (vino y, en menor medida, aceite e higos). Este menor peso del cereal explica la inexistencia de hojas de cultivo, que aparecen en otras aldeas de la tierra. Hay, sin embargo, una clara y neta separación de los campos abiertos cerealícolas y de las viñas y huertos. La propiedad cerealícola y vitícola se reparten de modo muy diferente. La primera presenta una elevada concentración. Algo más de un $10 \%$ de los vecinos disponen de explotaciones de veinte o más fanegas; en torno al $20 \%$ poseen explotaciones medias; frente a ellos, un tercio tiene explotaciones insuficientes y una cuarta parte no posee tierras de cereal. Sin embargo, los sectores menos acomodados controlan una parte mayoritaria y creciente de las viñas. Esta circunstancia nos permite pensar en un cierto equilibrio social.
\end{abstract}

Palabras clave: Historia rural; Baja Edad Media; Extremadura.

Abstract: The agrarian economy of Pozuelo, village of thetierra of Galisteo located in the base of the mountainous reliefs of the Central System, is characterized by the importance of other productions besides the cereal (wine and, in smaller measure, oil and figs). This smallest weight in the cereal explains the nonexistence of cultivationhojas that appear in other villages of the tierra. There is, however, a white and net separation of the open fields dedicated to the cereal and of the vineyards and orchards. The property of cereal lands and vineyards are distributed in a very different way. The first one presents a high concentration. Something more than $10 \%$ of the neighbors has exploitations of twenty or morefanegas; around $20 \%$ they possess exploitations stockings; in front of them, a third has insufficient exploitations and a fourth part doesn't possess cereal lands. However, the less suitable sectors control a majority and growing part of the vineyards. This circumstance allows us to think of a certain social balance.

Keywords: Rural History; Late Middle Ages; Extremadura.

${ }^{1}$ Trabajo realizado dentro del Proyecto «Fuentes documentales para la Historia de Extremadura» (Ref. 2PRO2A03), financiado por la Consejería de Educación de la Junta de Extremadura. 2003.

Fecha de recepción del artículo: abril 2003. Fecha de aceptación y versión final: diciembre

${ }^{2}$ Profesor de la Universidad de Extremadura.

«Anuario de Estudios Medievales», 34/1 (2004), pp. 249-278.- ISSN 0066-5061. 


\section{SUMARIO}

1. La propiedad agraria. Cuadro $\mathrm{n}^{\circ} 1$ : Distribucióngeográfica de la propiedad no vecinal. Cuadro $\mathrm{n}^{\circ}$ 2: Parcelas poseídas por no residentes (listado de parcelas). Cuadro $\mathrm{n}^{\circ}$ 3: La propiedad agraria en Pozuelo (1498). Cuadro $\mathrm{n}^{\circ} 4$ : Estructura de la propiedad vitícola. Cuadro $\mathrm{n}^{\circ}$ 5: Compraventa de propiedades agrarias.- II. La producción.- III. El paisaje agrario.- IV. Conclusión.

En 1498 comienza un pleito entre Pozuelo (Pozuelo de Zarzón) y El Campo (Villa del Campo), aldeas de Galisteo y Santibáñez, villa esta última integrada en el maestrazgo de la Orden de Alcántara. La información que nos suministra ${ }^{3}$ es de una gran importancia para la conflictividad horizontal, puesto que el enfrentamiento implica a otras comunidades de las dos jurisdicciones. Dicha información trasciende el propio conflicto y nos permite disponer de datos de extraordinario valor para el conocimiento de la estructura agraria de Pozuelo. Diego de la Torre, procurador del concejo de Galisteo, presenta un listado de más de un centenar y medio de propietarios en el que se precisan fundamentalmente la extensión de sus tierras y viñas (listado de propietarios) $^{4}$, y un interrogatorio en el que se enumeran las parcelas, más de trescientas sin contar las que aparecen como lindes, de ochenta y cinco propietarios (listado de parcelas) ${ }^{5}$. Contamos también con una tasación de las parcelas que sufrieron daños (tasación de daños) ${ }^{6}$ : doscientas cuarenta y nueve viñas, ciento treinta y cuatro tierras, algunos olivares y dos majadas, con indicación de su propietario. Todo ello hace de la información suministrada algo de un valor extraordinario al permitir analizar la propiedad campesina, el parcelario y la organización de terrazgo.

Los listados aludidos presentan algunas deficiencias que, sin embargo, no limitan en exceso sus posibilidades. El listado de propietarios nos permite hacernos una idea precisa de la propiedad agraria a finales de la Edad Media. Sin embargo, este listado, que debió hacerse con deseo de exhaustividad,

\footnotetext{
${ }^{3}$ AGS (Arch. General de Simancas), Consejo Real, leg. 34, $\mathrm{n}^{\circ}$ 7. El documento lo forman diversos cuadernillos: el 1 y el 3 no están numerados, pero si el 2 , el 4 y el 5 (cuando señalemos sólo el folio o folios nos referimos al cuadernillo 7-1).

${ }^{4}$ Fols. 279 r. -286 v.

${ }^{5}$ Fols. 311 r. -337 v.

${ }^{6}$ Fols. 259 r. -278 v.
}

«Anuario de Estudios Medievales», 34/1 (2004), pp. 249-278.- ISSN 0066-5061. 
presenta diversas omisiones. Esta circunstancia se ve con claridad al contrastarlo con la tasación de daños. En algunos casos, las diferencias son meramente formales: algunos propietarios son sustituidos por sus mujeres, sin duda por fallecimiento. Ambos listados, sin embargo, se presentan solamente con dos semanas de diferencia (veintisiete de julio y diez de agosto de 1498). En la tasación de daños aparecen nuevos propietarios. Sin embargo, se trata siempre de vecinos de otros núcleos de población que poseen viñas en Pozuelo ${ }^{7}$. Esto significa que no se ha registrado de forma exhaustiva en el listado de propietarios a los no-residentes. La propiedad de los vecinos de Pozuelo se ha enumerado, a lo que parece, de forma muy completa.

Una limitación de cierta importancia, de carácter más cualitativo que cuantitativo, es la escasa información que se ofrece sobre la ubicación de las viñas. No tenemos este problema para las tierras. Disponemos también de poca información para otros espacios agrarios, tales como huertos, linares u olivares. Posiblemente, su importancia sería mayor que su presencia documental. Una parte importante de la vida agraria, centrada en estos pequeños espacios que reciben una gran inversión de trabajo, no queda suficientemente reflejada. De todos modos, la información suministrada es muy rica y nos permitirá un estudio detallado y preciso de muchos aspectos de la realidad agraria.

\section{LA PROPIEDAD AGRARIA}

La información que nos suministra Diego de la Torre nos permite hacernos una idea cabal de la distribución de la propiedad agraria en Pozuelo a finales del siglo XV. Por razones obvias, los vecinos que no tienen ninguna propiedad no aparecen citados. Sin duda, constituye un aspecto del mayor interés precisar el porcentaje de propietarios y de no propietarios. Cualquier cálculo sobre el particular tendrá un cierto carácter hipotético. Disponemos de tres poderes concedidos por el concejo de Pozuelo en junio de 1498 y septiembre de 1499. Hemos contrastado los datos que nos suministran con el listado de propietarios, la tasación de daños y el listado de parcelas. Sobre ciento cincuenta vecinos (después de desestimar algunos casos dudosos),

\footnotetext{
${ }^{7}$ Algún caso, como el de Alfonso de Coria, vecino de Plasencia y propietario de siete viñas, es llamativo, pues parece que estamos ante una persona con propiedades importantes (fols. 261 r.-271 r.).

«Anuario de Estudios Medievales», 34/1 (2004), pp. 249-278.- ISSN 0066-5061.
} 
ciento veintisiete tienen algún tipo de propiedad $(84,67 \%)$. Esto supone que seis de cada siete vecinos poseen alguna heredad agraria. El acceso a la propiedad, en general, no es algo restrictivo, si bien, en muchos casos se trataría de muy pequeños propietarios que sólo contarían, y en muy pequeña media, con viñas o tierras. Las propiedades cerealícolas y vitícolas se reparten del siguiente modo entre los ciento cuarenta y dos vecinos de Pozuelo que aparecen en el listado de propietarios:

\begin{tabular}{||l|l|c||}
\hline Tipos de propiedad & $\mathrm{N}^{\circ}$ Propietarios & $\%$ \\
\hline tierras + viñas & 79 & 55,63 \\
\hline tierras & 24 & 16,90 \\
\hline viñas & 38 & 26,76 \\
\hline otros & $\begin{array}{l}1 \text { (posee medio } \\
\text { molino) }\end{array}$ & 0,70 \\
\hline
\end{tabular}

Por tanto, sólo algo más de la mitad de los propietarios vecinales poseen tierras y viñas, mientras que el resto sólo posee uno de los dos tipos de bienes.

Junto a la propiedad vecinal aparece la detentada por los no residentes. El interés de este grupo está relacionado con las peculiaridades que ofrece la economía de Pozuelo, pues son casi exclusivamente, como veremos, propietarios de viñas. Agrupados por unidades jurisdiccionales, la residencia de estos propietarios es la siguiente:

${ }^{8} \mathrm{Hemos}$ considerado como tales a todos aquéllos para los que no se precisa otra vecindad.

«Anuario de Estudios Medievales», 34/1 (2004), pp. 249-278.- ISSN 0066-5061. 
PROPIEDAD, PRODUCCIÓN Y PAISAJE AGRARIOS EN POZUELO

\section{Cuadro n ${ }^{0} 1$}

DISTRIBUCIÓN GEOGRÁFICA DE LA PROPIEDAD NO VECINAL

\begin{tabular}{|c|c|c|c|c|c|c|}
\hline & Props. & $\%$ & Tierras & Viñas & Otros & $\begin{array}{l}\text { Hered. } \\
(\%)\end{array}$ \\
\hline $\begin{array}{l}\text { Tierra de Galis- } \\
\text { teo }\end{array}$ & 22 & 64,70 & 5 & 35 & 3 & 68,25 \\
\hline Galisteo & 16 & 47,06 & 4 & 31 & 1 oliv & 57,14 \\
\hline Guijo & 3 & 8,82 & - & 2 & $1 / 2 \mathrm{~mol}$. & 6,35 \\
\hline Riolobos & 1 & 2,94 & 1 & - & - & 1,59 \\
\hline Valdeobispo & 1 & 2,94 & - & 1 & - & 1,59 \\
\hline Aceituna & 1 & 2,94 & - & 1 & - & 1,59 \\
\hline Plasencia & 3 & 8,82 & - & 8 & - & 12,70 \\
\hline Tierra de Coria & 3 & 8,82 & - & 3 & - & 4,76 \\
\hline Guijo de Coria & $2^{*}$ & 5,88 & - & 2 & - & 3,17 \\
\hline Morcillo & 1 & 2,94 & - & 1 & - & 1,59 \\
\hline $\begin{array}{l}\text { Jurisdicc. Cate- } \\
\text { dral de Coria }\end{array}$ & 2 & 5,88 & - & 2 & - & 3,17 \\
\hline $\begin{array}{l}\text { Villanueva (de } \\
\text { la Sierra) }\end{array}$ & 1 & 2,94 & - & 1 & - & 1,59 \\
\hline Santa Cruz & 1 & 2,94 & - & 1 & - & 1,59 \\
\hline $\begin{array}{l}\text { Tierra de Santi- } \\
\text { báñez (O.Alcan- } \\
\text { tara) }\end{array}$ & 3 & 8,82 & - & 4 & - & 6,35 \\
\hline El Campo & 2 & 5,55 & - & 3 & - & 4,76 \\
\hline Cadalso & 1 & 2,94 & - & 1 & - & 1,59 \\
\hline $\begin{array}{l}\text { Las Agallas } \\
\text { (Ciud.Rodrigo) } \\
\end{array}$ & 1 & 2,94 & - & 3 & - & 4,76 \\
\hline TOTAL & 34 & 99,99 & 5 & 55 & 3 & 99,99 \\
\hline
\end{tabular}

*Uno de ellos identificado simplemente como vecino del Guijo; el Guijo de Galisteo aparece frecuentemente como Guijito 
De estos datos podemos deducir algunas conclusiones sobre el reparto geográfico de la propiedad no vecinal. El componente jurisdiccional parece el condicionante más importante, seguido por la proximidad geográfica (cf. mapa 2). Casi dos tercios de los propietarios residen en la tierra de Galisteo y casi la mitad en la villa. Los vecinos de los lugares que rodean Pozuelo, aunque pertenezcan a otra jurisdicción, cuentan también con propiedades. Así sucede con Guijo de Coria, Santa Cruz y Villanueva. También están cercanos el resto de los lugares como Morcillo o Cadalso. La única excepción a esta proximidad está constituida por Las Agallas, aldea de Ciudad Rodrigo. Llama la atención la ausencia o escasa participación de vecinos de Coria y Plasencia. Sin duda, los grandes propietarios placentinos encuentran en las comarcas montañosas de su tierra lugares adecuados para la posible compra de viñas. El interés en las viñas de Pozuelo se explica por la economía predominante cerealícola de los lugares de origen de la mayor parte de los propietarios noresidentes, tales como Galisteo o Plasencia entre otros. María Gomez, vecina de Las Agallas, constituye una excepción doble por residir en un lugar distante y con una importante economía vitícola?

Para estudiar la propiedad rural, hemos definido diversos grupos en función de la propiedad cerealícola y luego hemos visto su relación con la propiedad vitícola (cuadro $\mathrm{n}^{0} 3$ ). También hemos cuantificado ésta última de modo independiente (cuadro $\mathrm{n}^{\circ} 4$ ). Los grupos de propiedad los hemos definido a partir de las pautas que nos señalan las propias ordenanzas de la tierra de Galisteo de 1531. En ellas se precisa que, en la vertiente derecha del Alagón, una yunta de labor debe arar cinco fanegas, lo que significa que una explotación de diez fanegas de sembradura (algo menos de cinco hectáreas) debería considerarse normal (en la vertiente izquierda son respectivamente ocho y dieciseis, algo menos de ocho hectáreas) ${ }^{10}$. La diferencia entre ambas vertientes se debe a la importancia que en la primera adquiere la producción rural no cerealícola, algo especialmente importante en Pozuelo.

Como sucede en otros entornos en los que se ha podido estudiar el nivel económico campesino, abundan aquéllos que disponen de explotaciones limitadas. El $24,49 \%$ no tiene tierras y sólo posee viñas y, en un caso, medio molino. El $59,18 \%$ de los propietarios posee menos de diez fanegas de

\footnotetext{
${ }^{9}$ Angel BERNAL EsTÉVEZ, El concejo de Ciudad Rodrigo y su tierra durante el siglo XV, Salamanca, 1989, pp. 373-384, espec. p. 375, n. 30.

${ }^{10}$ Julián Clemente Ramos, Ordenanzas de Galisteo (1531), Cáceres, 2001, p. 30.
} 
sembradura y concentra el $21,85 \%$ de la propiedad cerealícola. Aquellos que poseen entre diez y menos de quince fanegas (en realidad todos poseen entre diez y doce), suman el $14,28 \%$ de los propietarios y poseen el $18,37 \%$ de las tierras. En conjunto, el $22,45 \%$ posee entre ocho y doce fanegas, lo que podemos considerar dentro de la tierra de Galisteo y en particular en la vertiente derecha del Alagón una propiedad media. Por encima de las quince fanegas, el número de propietarios se reduce a la vez que aumentan su participación en la propiedad cerealícola. Los que poseen quince o más fanegas representan el $19,72 \%$ de los propietarios pero detentan el $59,77 \%$ de la propiedad; ocho propietarios $(5,44 \%)$ poseen treinta o más fanegas y acumulan el $28,12 \%$ del terrazgo cerealícola.

La estructura de la propiedad campesina en Pozuelo se ajusta rigurosamente a la estructura piramidal que se ha documentado en otros lugares ${ }^{11}$. Hay un amplio sector que se sitúa por debajo de lo que podemos definir como una situación media. Considerando a los no propietarios, que no aparecen reflejados directamente, incluiría a casi dos tercios de la población. El grupo que podemos considerar medio (ocho a quince fanegas de sembradura; normalmente entre ocho y doce) engloba a algo menos de una cuarta parte. El colectivo de campesinos acomodados (mas de quince fanegas de sembradura) representa un proporción similar o algo inferior. Los campesinos ricos (mas de treinta fanegas de sembradura) son una minoría, pero acumulan una parte muy importante de la propiedad cerealícola.

El cultivo vitícola, al igual que seguramente los huertos y comunales, cumple un papel de equilibrio en la sociedad de Pozuelo. No hay una correspondencia positiva entre éste y el cerealícola. Aquéllos que no tienen tierras de pan llevar poseen viñas $(97,22 \%)$ más frecuentemente que el resto y su propiedad vitícola media, excluyendo la no vecinal, solo es superada por los que poseen entre treinta y treinta y nueve fanegas. El grupo sin propieda-

${ }^{11}$ H.E. HallaM, Some Thirteenth-Century Censuse, "Economic History Review", 10 (19571958, pp. 343 y 349; F. LEVEROTTI, La famiglia contadina lucchese all 'inizio dell'400, "Strutture familiari, epidemmie, migrazioni nell'Italia medievale", Napoles, 1984, p. 255; Leopold GENICOT, Comunidades rurales en el occidente medieval, Barcelona, 1993, pags. 70-2; la crisis bajomedieval aumentó, a veces de forma sensible, la extensión de las tenencias: Christopher DYER, Niveles de vida en la Baja Edad Media, Barcelona, 1991, p. 184. Para la península: Ricardo CIÉRVIDE y José Angel SESMA, Olite en el siglo XIII. Población, economía y sociedad de una villa navarra en plena Edad Media, Pamplona, 1980, pp. 87-97; Antoni FURIÓ, Tierra, familia y transmisión de la propiedad en el País Valenciano durante la Baja Edad Media, "Relaciones de poder, de producción y parentesco en la Edad Media y Moderna", Madrid, 1990, pp. 309-310; Mercedes BORRERO FERNÁNDEZ, El mundo rural sevillano en el siglo XV: Aljarafe y Ribera, Sevilla, 1983, p. 240.

«Anuario de Estudios Medievales», 34/1 (2004), pp. 249-278.- ISSN 0066-5061. 
des cerealícolas posee el $27,7 \%$ del viñedo; en conjunto, aquellos que cuentan con menos de diez fanegas de sembradura acumulan el $59,60 \%$, mas de dos tercios de la propiedad estrictamente vecinal. Su peso demográfico es menor que su participación en la propiedad vitícola. Aquéllos que poseen entre diez y diecinueve fanegas, el 21,08\% de los propietarios, sólo acumulan el 13,35\% de las viñas, y los que disponen de veinte o más fanegas de sembradura, el $12,92 \%$ de los propietarios, el $14,67 \%$. Los más pequeños propietarios parecen tener un mayor interés en la explotación de viñas, mientras que los propietarios medios y los campesinos acomodados y ricos tienen poca inclinación hacia este cultivo. La mayor disponibilidad de mano de obra entre los campesinos pobres explica esta mayor dedicación a una actividad que requiere un instrumental muy limitado pero una gran inversión en trabajo. La rentabilidad de la vid debería disminuir conforme fuera necesario utilizar mano de obra ajena a la propia familia. En contra de lo que pudiera parecer, la producción vitícola encontraría en los campesinos pobres sus cultivadores ideales.

En general, la propiedad vitícola está poco concentrada. La mayor parte de los propietarios no tienen más de dos cuartas de viña. Algo más de un tercio de ellos $(36,69 \%)$ alcanza o supera esta extensión. Los que tienen entre una y 1,75 cuartas acumulan el $23,19 \%$ del terrazgo vitícola, y los que poseen entre dos y 2,75 , el $25,16 \%$. Los que no superan las tres cuartas totalizan el $52,07 \%$. Los que alcanzan las cinco cuartas poseen el $25,16 \%$. La concentración de la propiedad es menor que en las tierras de pan llevar. A ello hay que añadir, como hemos indicado, que no es frecuente la acumulación de tierras de cereal y viñas. De hecho, los mayores propietarios de viñas (cinco cuartas o más) tienen extensiones cerealícolas medias de carácter módico (cuatro fanegas). Es, sobre todo, este aspecto el que nos permite sostener que el viñedo está repartido entre todos los grupos campesinos.

Hasta ahora hemos hablado de la propiedad, mayoritaria sin duda, detentada por los vecinos de Pozuelo. Como hemos indicado, otras personas residentes en otras localidades también poseen propiedades. Esta propiedad es, como ya hemos indicado, casi exclusivamente vitícola, lo que se explica por la economía predominantemente cerealícola de los lugares de residencia de estos propietarios. En el listado de propietarios sólo aparecen como poseedores de viñas, salvo uno que posee medio molino; lo mismo sucede en la tasación de daños, con treinta y seis viñas. En el listado de parcelas, casi la totalidad de la propiedad no vecinal consiste en viñas, cuarenta y tres, frente a dos tierras y un olivar. No es algo casual. En este listado se enumeran 
todos los bienes de algunos forasteros. Los resultados ofrecen una total homogeneidad:

\section{Cuadro no 2}

PARCELAS POSEÍDAS POR NO RESIDENTES

(LISTADO DE PARCELAS)

\begin{tabular}{||l|c|c|c||}
\hline & Tierra & Viña & Olivar \\
\hline Pablo Antón & - & 1 & - \\
\hline Diego de Bárcena & - & 1 & - \\
\hline viuda Martín González & - & 5 & 1 \\
\hline Pedro de Montoya & - & 4 & - \\
\hline Tristán & - & 4 & - \\
\hline Mari Gómez & - & 3 & - \\
\hline Alfonso Domínguez & 1 & - & - \\
\hline Pedro del Pozuelo & - & 2 & - \\
\hline TOTAL & 1 & 20 & 1 \\
\hline
\end{tabular}

Podemos afirmar con total seguridad que la propiedad vitícola es la única que presenta interés para este grupo de propietarios avecindados en otras poblaciones. Todas las informaciones inciden en la misma dirección. Por otro lado, es llamativa la importancia relativa de esta propiedad. Algunos de los mayores propietarios de viñas no son vecinos de Pozuelo y la propiedad media detentada es de 3,11 cuartas, muy superior a la de cualquier otro grupo. En el listado de propietarios representan el $6,8 \%$, pero poseen el $12,36 \%$ del viñedo. Son el único grupo cuya peso demográfico es netamente inferior a su participación en la propiedad vitícola. Hay, por tanto, un sector en expansión que lo forman los forasteros que acumulan viñas en Pozuelo. 


\section{Cuadro no $3 / 1$}

\section{LA PROPIEDAD AGRARIA EN POZUELO $(1498)^{*}$}

a) TierRas Cerealícolas

\begin{tabular}{||c|c|c|c|c||}
\hline $\begin{array}{c}\text { Explotac. } \\
\text { (Fanegas) }\end{array}$ & $\begin{array}{c}\text { Propiet. } \\
\mathrm{N}^{\circ}\end{array}$ & $(\%)$ & Fanegas & $\%$ \\
\hline 0 & 36 & 24,49 & - & - \\
\hline $1-4$ & 19 & 12,92 & 53,5 & 4,33 \\
\hline $5-9$ & 32 & 21,77 & 216,5 & 17,52 \\
\hline $10-14$ & 21 & 14,28 & 227 & 18,37 \\
\hline $15-19$ & 10 & 6,80 & 156 & 12,63 \\
\hline $20-29$ & 11 & 7,48 & 235 & 19,02 \\
\hline $30-39$ & 6 & 4,08 & 194,5 & 15,74 \\
\hline$\geq 40$ & 2 & 1,36 & 153 & 12,38 \\
\hline No vecinal & 10 & 6,80 & - & - \\
\hline TOTAL & 147 & 99,98 & $1.235,5$ & 99,99 \\
\hline
\end{tabular}

* dos propietarios disponen de una tierra y uno de ellos de media cuarta de viña heredada; tres propietarios poseen una tierra cada uno, una heredada y dos compradas, que convierten en viñas, una de las cuales tiene una extensión de 1,5 cuartas. Estos propietarios no se han computado en este cuadro al no precisarse la extensión de su propiedad cerealícola. Hemos procedido del mismo modo con la iglesia parroquial de San Pedro de Pozuelo, que posee cincuenta fanegas de tierra y una cuarta de viña, al no tratarse de un propietario particular. No se concreta la extensión de 12,5 viñas, un pedazo de viña y un majuelo. 


\section{Cuadro n ${ }^{0} 3 / 2$}

\section{LA PROPIEDAD AGRARIA EN POZUELO \\ $(1498)^{*}$}

b) VIÑAS

\begin{tabular}{||l||c|l|l|l|l||}
\hline $\begin{array}{l}\text { Explot. } \\
\text { (Fanegas) }\end{array}$ & $\begin{array}{c}\text { Pro- } \\
\text { piet. }\end{array}$ & No prop. & cuartas & $\%$ & Prop. Media \\
\hline 0 & 35 & 1 & 62,75 & 27,70 & 1,90 \\
\hline $1-4$ & 14 & 5 & 24 & 10,60 & 1,29 \\
\hline $5-9$ & 27 & 5 & 48,25 & 21,30 & 1,56 \\
\hline $10-14$ & 15 & 6 & 21,75 & 9,60 & 1,21 \\
\hline $15-19$ & 6 & 4 & 8,5 & 3,75 & 0,94 \\
\hline $20-29$ & 8 & 3 & 16,75 & 7,39 & 1,52 \\
\hline $30-39$ & 6 & - & 14,5 & 6,40 & 2,42 \\
\hline$\geq 40$ & 2 & - & 2 & 0,88 & 1 \\
\hline $\begin{array}{l}\text { No veci- } \\
\text { nal }\end{array}$ & 9 & 1 & 28 & 12,36 & 3,11 \\
\hline TOTAL & 122 & 25 & 226,5 & 99,98 & 1,54 \\
\hline
\end{tabular}

* Idem, Cuadro 3/1 


\section{Cuadro $n^{0} 4$}

ESTRUCTURA DE LA PROPIEDAD VITÍCOLA

\begin{tabular}{||l|l|l|l|l||}
\hline Cuartas & $\left(\mathrm{N}^{0}\right)^{*}$ & Propiet $\%$ & Cuartas** & $\%$ \\
\hline 0 & 25 & 17,98 & - & - \\
\hline$<1$ & 19 & 13,70 & 8,5 & 3,72 \\
\hline $1 \leq 2$ & 44 & 31,65 & 53 & 23,19 \\
\hline $2 \leq 3$ & 26 & 18,70 & 57,5 & 25,16 \\
\hline $3 \leq 4$ & 9 & 6,47 & 27,5 & 12,03 \\
\hline $4 \leq 5$ & 6 & 4,32 & 24,5 & 10,72 \\
\hline$\geq 5$ & 10 & 7,19 & 57,5 & 25,16 \\
\hline TOTAL & 139 & 100,01 & 228,5 & 99,98 \\
\hline
\end{tabular}

* En once casos no se precisa la extensión poseída, aunque si la condición de propietarios. ** Se computan las dos viñas de 0,5 y 1,5 cuartas no incluidas en el Cuadro 3.

En el listado de propietarios se precisa también, de modo habitual, el origen heredado o comprado de la propiedad. Esto nos permite aproximarnos al mercado de la propiedad agraria. Este mercado es bastante dinámico, especialmente para las viñas. Una quinta parte de la propiedad cerealícola $(20,07 \%)$ y casi la mitad del viñedo $(47,88 \%)$ han sido compradas por sus titulares.

Tierras de cereal y viñas (cf. cuadro 5) presentan dos perfiles claramente definidos y diferenciados. Casi todos los grupos han adquirido una cantidad próxima a la quinta parte de las tierras de cereal que poseen. Sin embargo, esta realidad esconde, en función del distinto grado de disfrute de la propiedad agraria, realidades bien distintas. Los poseedores de menos de cinco fanegas sólo han adquirido en conjunto 5,5 fanegas, lo que supone una media de 0,29 fanegas/persona. Esta media va a ir subiendo para los diversos grupos, superando la fanega aquéllos que poseen entre cinco y menos de veinte fanegas. Para los más acomodados esta cantidad se eleva sucesivamente a 4,5, 9,87 y 13 fanegas/persona, a la vez que aumenta en líneas generales el 
porcentaje de las tierras obtenidas por compra. Los que poseen veinte o más fanegas, $12,92 \%$ de los propietarios que poseen el $47,14 \%$ de la propiedad cerealícola, han adquirido el $49,24 \%$ de la tierra vendida; los que cuentan con diez a diecinueve, $22,63 \%$ de los propietarios y $31 \%$ de las tierras de cereal, el 30,30\%; y aquéllos que poseen menos de diez fanegas, $40,15 \%$ de los propietarios (excluidos los que no poseen nada) y el $21,85 \%$ de la propiedad cerealícola, el $20,54 \%$. Estos datos nos muestran un proceso de muy lenta acumulación de tierras por parte de los campesinos más acomodados.

La propiedad vitícola presenta un comportamiento diferente y fue un elemento de equilibrio en la sociedad rural. Aquéllos sin propiedades cerealícolas presentan un perfil muy dinámico. Este colectivo ha adquirido más de la mitad de su propiedad vitícola, por lo que la adquisición media por persona es de casi una cuarta. Además, acumulan el $42,83 \%$ de la propiedad vendida, muy por encima de cualquier otro grupo. Esto significa que aquéllos campesinos menos acomodados tienen ciertos recursos que les permiten comprar propiedades. No parece sorprendente que su esfuerzo se dirija a heredades que requieren una gran inversión de trabajo y que tienen una elevada productividad. Por tanto, un grupo que representa algo más de una cuarta parte de los propietarios $(26,28 \%)$ y que detenta casi la tercera parte de la propiedad vitícola $(31,61 \%)$ adquiere casi la mitad de las viñas vendidas $(42,83 \%)$. Para aquéllos que poseen entre una y menos de diez fanegas, los porcentajes respectivos son el 37,23, el 36,40 y el 23,79; los que poseen diez o más fanegas, el $36,50 \%$ de los propietarios, acumulan el $31,99 \%$ de la propiedad vitícola y adquieren el $31,38 \%$ de la propiedad vendida. Por tanto, los campesinos sin tierras de cereal se convierten en la base de la economia vinícola y todo nos hace pensar que están incrementando su peso en este campo con relativa intensidad. Los demás propietarios, incluidos los que lo son en una medida limitada, tienen un interés menor. Economía cerealícola y vitícola aparecen sustentadas por distintos grupos campesinos, realidad con un alto significado social.

Dentro de la propiedad vitícola presentan una situación de gran interés los propietarios no avecindados en Pozuelo. Tenemos datos sólo para cinco. De ellos, dos han recibido sus viñas por herencia y tres las han comprado. La propiedad heredada alcanza el $16,67 \%$ y la comprada el $83,33 \%$. El grupo de los propietarios no residentes, más importante como hemos visto de lo que podría parecer por los datos presentados en el listado de propietarios, parece un grupo en expansión que quizás no tuviera excesiva antigüedad. A esto hay que unir que, junto a los que no poseen tierras de cereal, es el único grupo 
cuya participación en el mercado de compra/venta de viñas es claramente superior a su peso demografico. Ha adquirido el 17,14\% de la extensión vitícola vendida, cuando sólo representan el $6,8 \%$ de los propietarios y acumulan el $12,36 \%$ de la propiedad. Este interés de los no residentes quizás esté vinculado al desarrollo de la economía vitícola en Pozuelo, cuya antigüedad desconocemos pero que sin duda se presenta como un cultivo en expansión a finales del siglo XV. Por otro lado, la producción vinícola es claramente deficitaria en la tierra de Galisteo ${ }^{12}$, lo que sin duda está detrás del claro interés que manifiestan por esta actividad los vecinos de la villa.

\section{Cuadro n ${ }^{0}$ 5/1}

COMPRAVENTA DE PROPIEDADES AGRARIAS* TIERRAS DE CEREAL

\begin{tabular}{||l|l|l|l|l|l||}
\hline $\begin{array}{l}\text { Explot. } \\
\text { (Fanegas) }\end{array}$ & $\mathrm{N}^{\circ}$ Prop. & $\begin{array}{l}\text { Compra- } \\
\text { dores } \%\end{array}$ & $\begin{array}{l}\text { Fanegas } \\
\text { Compr. }\end{array}$ & $\begin{array}{l}\text { Fanegas } \\
\text { Compr./ } \\
\text { Propiet. }\end{array}$ & $\begin{array}{l}\text { Fanegas } \\
\text { Compr. } \\
\text { \% prop. } \\
\text { poseída) }\end{array}$ \\
\hline 0 & 36 & - & - & - & - \\
\hline $1-4$ & 19 & 21,05 & 5,5 & 0,29 & 10,28 \\
\hline $5-9$ & 32 & 25,81 & 35 & 1,25 & 18,09 \\
\hline $10-14$ & 21 & 52,38 & 45 & 2,5 & 22,84 \\
\hline $15-19$ & 10 & 11,11 & 15 & 1,67 & 10,71 \\
\hline $20-29$ & 11 & 36,36 & 45 & 4,5 & 20,93 \\
\hline $30-39$ & 6 & 83,33 & 39,5 & 9,87 & 29,37 \\
\hline $40-.$. & 2 & 100 & 13 & 13 & 24,53 \\
\hline No vecinal & 10 & - & - & - & - \\
\hline TOTAL & 147 & 24,14 & 198 & 1,47 & 20,07 \\
\hline
\end{tabular}

* Para la obtención de medias y porcentajes hemos excluido a aquellos propietarios para los que no se especifica la parte comprada y la heredada.

${ }^{12}$ Julián Clemente Ramos, Ordenanzas de Galisteo (1531), p. 31.

«Anuario de Estudios Medievales», 34/1 (2004), pp. 249-278.- ISSN 0066-5061. 
PROPIEDAD, PRODUCCIÓN Y PAISAJE AGRARIOS EN POZUELO

\section{Cuadro $\mathrm{n}^{0} \mathbf{5} / 2$}

COMPRAVENTA DE PROPIEDADES AGRARIAS*

b) VIÑAS**

\begin{tabular}{||l||l|l|l|l||}
\hline $\begin{array}{l}\text { Explot. } \\
\text { (Fanegas) }\end{array}$ & $\begin{array}{l}\text { Comprad. } \\
(\%)\end{array}$ & $\begin{array}{l}\text { Cuartas } \\
\text { compr. }\end{array}$ & $\begin{array}{l}\text { Cuartas } \\
\text { Compr./ } \\
\text { Propiet }\end{array}$ & $\begin{array}{l}\text { Cuartas } \\
\text { Compr. } \\
\text { (\% Prop. } \\
\text { poseída) }\end{array}$ \\
\hline 0 & 44,44 & 32,5 & 0,98 & 52,21 \\
\hline $1-4$ & 21,05 & 2 & 0,12 & 11,76 \\
\hline $5-9$ & 35,48 & 15,25 & 0,56 & 41,22 \\
\hline $10-14$ & 23,21 & 8 & 0,4 & 47,76 \\
\hline $15-19$ & 20 & 1 & 0,11 & 18,18 \\
\hline $20-29$ & 45,45 & 4,75 & 0,53 & 41,30 \\
\hline $30-39$ & 66,66 & 8,5 & 1,7 & 73,91 \\
\hline $40-\ldots$ & 100 & 0,5 & 0,5 & 50,00 \\
\hline No vecinal & 50 & 12,5 & 1,78 & 83,33 \\
\hline & & & & $* * * 0,67$ \\
\hline TOTAL & 36,17 & 85 & & 47,88 \\
\hline
\end{tabular}

*Idem Cuadro 5/1

$* *$ Cuartejón $=1 / 4$ cuarta.

$* * *$ Excluido el colectivo no vecinal, el índice es 0,60.

La imagen general de la propiedad campesina en Pozuelo aparece con gran nitidez en las fuentes que hemos utilizado. La propiedad cerealícola se reparte de una forma muy desigual y rígidamente piramidal, con una minoría limitada que acumula una parte importante de la propiedad y una gran mayoría con explotaciones bastante limitadas y en algunos casos, menos numerosos, sin propiedad alguna. Este perfil tiende a reforzarse, pero muy lentamente, por medio de las compra/ventas. El viñedo responde a una pauta muy diferente. La distribución de su propiedad es mucho más igualitaria. Los propietarios más modestos disponen de una parte sustancial y muestran un dinamismo comprador que les permitiría incrementar de forma paulatina su participación. El viñedo es, sobre todo, el terreno del campesinado pobre, que 
encuentra en un cultivo más exigente y productivo una dedicación preferente. $\mathrm{Su}$ dinamismo comprador es el mayor indicio de un cierto equilibrio social. La pobreza extrema sería menor de lo que parecen reflejar los cuadros estadísticos. El viñedo es también objeto de interés por parte de vecinos de poblaciones colindantes o de otras próximas de preferente dedicación cerealícola.

\section{LA PRODUCCIÓN}

Los datos suministrados sobre la producción agraria son limitados, pero tienen una gran importancia por su carácter cuantitativo. Sin duda, hay que interpretarlos en el contexto en el que aparecen. La parte de la tierra de Galisteo situada a la derecha del río Alagón presenta un contraste claro respecto de la situada a la izquierda, que tiene una clara vocación cerealíco$\mathrm{la}^{13}$. La zona en que se ubica Pozuelo se sitúa junto a las primeras estribaciones del Sistema Central, cerca de las comarcas serranas de Gata y Las Hurdes. La existencia de mayores pendientes y suelos menos consistentes explican una menor dedicación cerealícola y, consiguientemente, un mayor desarrollo del cultivo de la vid. Las ordenanzas de Galisteo de 1531, que reflejan una realidad consolidada que podemos retrotraer sin ninguna duda a finales del siglo $\mathrm{XV}$, constatan la especial importancia que este cultivo tiene en Pozuelo, la única aldea que se cita explícitamente en relación con la vendimia $^{14}$. Sin duda, esta situación es la que explica el interés que tienen vecinos de otras localidades en su viñedo. Dentro de la información que manejamos aparecen tierras que están siendo o han sido plantadas de viñas. Pedro Manzano tiene un pedazo de tierra "que esta puesta en ella çierta parte de viña"; tres propietarios poseen tierras que han comenzado a plantar de viñas; y dos propietarios, viñas que sólo están parcialmente plantadas, seguramente debido a que anteriormente tenían otra dedicación ${ }^{15}$. Sólo se documenta, sin embargo, un majuelo de Juan de la Zarza ${ }^{16}$.

\footnotetext{
${ }^{13}$ Julián Clemente Ramos, Ordenanzas de Galisteo (1531), pp. 29-30

${ }^{14}$ Julián Clemente Ramos, Ordenanzas de Galisteo (1531), p. 31.

${ }^{15}$ Fols. 282 v., 284 r., 327 v. y 331 r.-332 v. ("viña de la de Marcos Fernandes de la qual esta puesto un pedaço de viña"; "viña de Juan de Garçi Fernandes, la qual esta puesta viña fasta media quarta de viña").

${ }^{16}$ Fol. 284 r.
}

«Anuario de Estudios Medievales», 34/1 (2004), pp. 249-278.- ISSN 0066-5061. 
La economía agraria de Pozuelo presenta un perfil de transición entre la economía de montaña y la de llanura dentro de la Extremadura bajomedieval. No es en sentido estricto una zona de montaña, aunque al norte del término se encuentran ya alturas que superan los mil metros.

El espacio agrario de Pozuelo se presenta como una realidad diversificada. Aparecen "panes, e viñas, e huertos, e olivares, e naranjales, e figuerales, e otros arboles, e plantas" (fol. 22v) ${ }^{17}$. Junto al espacio cerealícola, diversas producciones obtenidas de huertos $\mathrm{y}$, sobre todo, viñas adquieren suficiente importancia. Olivos, higueras y cítricos se cultivan en estos espacios, al margen del desarrollo limitado del olivar como espacio individualizado.

En la respuesta real a las protestas de los procuradores de Pozuelo aparecen datos cuantitativos del mayor interés sobre la producción agraria. Inicialmente, los daños alcanzaron "fasta mill fanegas de pan e dos mill arrovas de vino e quinientas arrovas de azeyte"; posteriormente, se incrementaron en "otros dos mill fanegas de pan e dos mill cantaras de vino" (fol. 22r). El interrogatorio realizado en el pleito nos ofrece cantidades no muy diferentes, añadiendo alguna otra información. Uno de los testigos estima las pérdidas en "tres mill arrovas de vino e dosientas fanegas de fijos" (fol. 102v) y Pedro Carnaceda en "dos mill arrovas de vino, e a los señores de las olivas mas de çient arrovas de azeyte, e a los señores de las higueras dosientas hanegas de higo por ogaño" (fol. 137). Los daños producidos, que consideramos de modo teórico proporcionales a la producción total, serían los siguientes:

\footnotetext{
${ }^{17}$ Más adelante se presenta otra imagen muy similar al aludir los vecinos de Pozuelo a la "fuerça e daños que les han fecho en sus bacas que disen majadas, e los panes, e viñas, e huertas e huertos, e en oliveras, e en otras muchas arvoles e heredades" (fol. 48 v.).

«Anuario de Estudios Medievales», 34/1 (2004), pp. 249-278.- ISSN 0066-5061.
} 


\begin{tabular}{||l|l|l|l|l||}
\hline & Cereal & Vino & Aceite & Higos \\
\hline Daños & 3.000 fanegas & $\begin{array}{l}3.000-2000 \\
\text { arrobas }\end{array}$ & $500-100$ arrobas & 200 fanegas \\
\hline LiTROS $^{18}$ & 166.503 & $48.399-32.266$ & $6.281,5-1.256,3$ & $11.100,2$ \\
\hline
\end{tabular}

Considerando, como hemos señalado, que haya una proporción entre estas cantidades y la producción total llama la atención la importancia de la producción vinícola y de aceite e higos, producciones obtenidas en los campos cercados frente a las campos abiertos cerealícolas. Las cantidades, en todo caso, no son suficientemente significativas si no se estima su valor. No disponemos, al menos hasta ahora, de precios relativos a la zona. Sin embargo, podemos esbozar, a partir de los precios de estos productos documentados en otras zonas, el valor de la producción, lo que nos acercaría en mayor medida a la importancia real de las diferentes producciones agrarias. Hay que considerar que, por unidad de peso, el vino y el aceite son en general sensiblemente más caros que el cerea ${ }^{19}$. Considerando que el cereal producido

${ }^{18}$ Las equivalencias más habituales en la provincia de Cáceres son las siguientes: Fanega $=$ 55,501 lts.; cántara $=16,133$ lts; arroba de aceite $=12,563$ lts. (Pesas, medidas y monedas, Granada, $1986^{2}$, pp. 28-9). Arroba y cantara, medida ponderal la primera y de capacidad la segunda, son prácticamente equivalentes, pues constan igualmente de ocho azumbres (Cortes de los antiguos reinos de León y de Castilla, Madrid, 1861, p. 534; José Damián GoNZÁLEZ ARCE, Cuadernos de ordenanzas y otros documentos sevillanos del reinado de Alfonso X, "Historia. Instituciones. Documentos", 16 (1989), 103-132, p. 117).

${ }^{19}$ En Trujillo, entre 1507 y 1509 , la libra de pan de trigo se sitúa normalmente entre dos-tres maravedís; la panilla de aceite en 1508 tiene un precio regulado de diez maravedís $\left(\mathrm{M}^{\mathrm{a}}\right.$ de los Angeles SÁNCHEZ RUBIO, El concejo de Trujillo y su alfoz en el tránsito de la Edad Media a la Edad Moderna, Badajoz, 1993, pp. 420-1). La panilla equivale normalmente en Castilla a $1 / 4$ de libra $(0,115$ gramos); en Cáceres, sin embargo, se presenta la equivalencia 1 litro $=2,187$ panillas, con lo que la panilla contiene 0,46 litros, y tendría un peso cercano a la libra (Joaquín VALLVÉ BERMEJO, Notas de metrología hispano-árabe. II. Medidas de capacidad, "Al-Andalus", XLVII/1 (1977), pp. 30 y 119; Manuel BASAS, Antiguos sistemas de pesos y medidas, Bilbao, 1980 , p. 46; Pesas, medidas y monedas, Granada, $1986^{2}$, p. 29). Los oficiales de Medellín que fueron a visitar los montes en 1540 pagaron la fanega de pan a 113,3 maravedís; la arroba de vino, excluido el añejo, a 102 maravedís; y la arroba de aceite, a 306 maravedís (ẢGS, Consejo Real, Leg. 140, exp. 2-IV, fol. 135; índices: 100, 309,70 y 1.193,42). En la tasación fiscal realizada en 1485 en Paterna del Campo se señalan, entre otros, los siguientes valores: arroba de aceite, 65 maravedís; arroba de vino, 20 maravedís; fanega de trigo, 90 maravedís, y de cebada, 70 maravedís (Mercedes BORRERO FERNÁNDEZ, El mundo rural sevillano en el siglo XV, pag. 342 ; índices: 319,$13 ; 76,45 ; 100 ;$ y 77,78). En Palencia, los precios del trigo (fanega), la cebada (fanega) y el vino blanco, tinto y de la tierra (cántara) en 1478 y 1516 son respectivamente: 190 , $69,5,64,88$ y 27 maravedís en 1478 y 79,2, 62,5, 96, 120 y 60 maravedís en 1516 (Hilario CASADO ALONSO, Producción agraria, precios y coyuntura económica en las diócesis de Burgos y Palencia a fines de la Edad Media, "Studia Histórica. Historia Medieval", X [1992], pp. 86-7 y 92; el vino de la tierra alcanza el índice 111,18 respecto del trigo y la cebada el 49,03). En Granada en 1498, año de precios moderados, la fanega de trigo vale 65 maravedís y el azumbre 
fuera predominantemente trigo y en menor medida cebada y centeno, pensamos que podemos mantener el índice 100 para el cereal, el 175 para el vino y el 500 para el aceite (no disponemos de información sobre precios de los higos); calculando si es necesario la producción media y dando a la cerealícola el valor 100, el peso económico de las distintas producciones sería el siguiente:

\begin{tabular}{||c|c|c|c|}
\hline & Cereal & Vino & Aceite \\
\hline Producción estimada & 100 & 42,39 & 22,63 \\
\hline$\%$ & 60,66 & 25,69 & 13,71 \\
\hline
\end{tabular}

Sin dar a estos datos más que un valor meramente orientativo, podemos certificar sin ninguna duda la importancia que el vino y el aceite tenían para la economía de Pozuelo. Esto significa que huertas y, sobre todo, viñas jugarían un papel fundamental en la producción ${ }^{20}$. Esta circunstancia tiene una importancia que trasciende su mero significado económico para tener una gran relevancia social. Aunque ocupando espacios mucho menos extensos, las viñas debieron alcanzar una productividad mucho más elevada que las tierras de cereal, lo que beneficiaría a los sectores más modestos del campesinado. La propiedad vitícola se presenta, de este modo, como una base económica razonable. Sin duda, debe considerarse este factor para explicar el relativo equilibrio que presenta la sociedad campesina de Pozuelo y que se manifiesta en la compra de heredades por parte de aquéllos que no poseen tierras de cereal. Su interés preferente en las viñas adquiere ahora todo su significado económico. En definitiva, junto al cereal, base de la actividad

de vino 6 maravedís (Juan Andres LUNA DíAz, Notas para el estudio de los precios y salarios en Granada (1492-1502), “Chronica Nova”, 12 (1981), pp. 114-5; índice 100 y 256). En Toledo, entre 1400 y 1475 , el índice 100 del precio del trigo si sitúa en 3,14 reales/fanega, el de la cebada en 1,62 , el del centeno en 1,43, el del vino en 1,29 reales/arroba, y el del aceite en 5,29 reales/arroba (Ricardo IZQUIERDO BENITO, Precios y salarios en Toledo en el siglo XV (14001475), Madrid, 1982, pp. 10-19; índices: 100, 51,59; 45,54; 141,33; y 744,44).

${ }^{20} \mathrm{La}$ importancia de la producción agraria no cerealícola se mantiene e incluso aumenta a lo largo de la época moderna. A finales del siglo XVIII, según el interrogatorio de la Real Audiencia de Extremadura, "ai tres cosechas... que estas por quinquenio aszienden las de granos dos mil de trigo y tres mil y zinco fanegas de zenteno, sus prezios el trigo a veinte y quatro y el zenteno a diez y ocho reales; la de vino asziende a quatro mil y quinientos cantaros, su prezio a diez reales; el de azeite asziende por quinquenio a mil cantaros, su prezio por quinquenio a quarenta reales el cantaro" (Interrogatorio de la Real Audiencia. Extremadura a finales de los tiempos modernos. Partido de Coria, Badajoz, 1994, p. 418). El valor de la producción de vino y aceite representa el $45,43 \%$ del total. 
económica de los campesinos medios y acomodados, las viñas, sobre todo, y los espacios cercados en general, refugio de los campesinos más modestos, tienen una gran importancia económica, lo que les permite tener una función de equilibrio en el tejido social. El perfil económico de Pozuelo muestra una clara influencia de las pautas que pueden asignarse a la economía de montaña en la Extremadura bajomedieval, modelo que se opone abiertamente a la economía de llanura, muchos más dependiente del cultivo del cereal.

\section{EL PAISAJE AGRARIO}

El paisaje que nos presenta la fuente que manejamos nos permite sólo acercarnos al espacio agrarizado. El espacio adehesado, privado y comunal, queda totalmente fuera de nuestra información. Muy posiblemente, la dehesa boyal de Pozuelo se situaría a finales del siglo XV en la zona occidental del término municipal, en donde aparece actualmente la dehesa de Pozuelo ${ }^{21}$. Esta zona occidental estaría ocupada por espacios adehesados y baldíos destinados a la ganadería local $^{22}$. La ausencia de información no nos permite precisar nada más que estas meras hipótesis.

Los datos ofrecidos sobre el paisaje agrario, pese a su carácter incompleto, son de un extraordinario valor. Conocemos los linderos de más de trescientas parcelas y la ubicación de muchas de ellas (cf. mapa 1). Disponemos también de información diversa que nos permite conocer mejor la realidad de los diversos espacios productivos.

El paisaje rural de Pozuelo es un paisaje fragmentado, muy parcelado. Este rasgo se une a la clara concentración de los diversos cultivos. Tierras, viñas, huertos y demás tipos de espacios agrarios tienden a agruparse. No aparecen, sin embargo, hojas de cultivo cerealícolas, pese a que se documentan décadas más tardes, y quizás ya existiesen a finales del siglo $\mathrm{XV}$, en el este y sur de la tierra de Galisteo ${ }^{23}$.

\footnotetext{
${ }^{21}$ El único propio de Pozuelo de gran extensión -69,71 has- desamortizado en el siglo XIX aparece junto a esta dehesa (Boletín Oficial de Ventas de Bienes Nacionales de la Provincia de Cáceres, $\mathrm{n}^{\circ} 1.445$, pág. 4)

${ }^{22}$ Aparecen entre los espacios agrarios dos majadas ( $\mathrm{n}^{\circ}$ 7-2, fol. 101 r.: "quemaron dos majadas en medio de los dichos panes"; se enumeran entre los espacios que han sufrido daños: fol. $278 \mathrm{v}$.); sólo podemos precisar que eran terrenos de aprovechamiento ganadero (fol. $48 \mathrm{v}$ : se habla de la "fuerça e daños que les han fecho en sus bacas que disen majadas").

${ }^{23}$ Julián Clemente Ramos, Ordenanzas de Galisteo (1531), pp. 26-7.
} 
La concentración de tierras y viñas no ofrece ninguna duda. Conocemos los linderos de ciento setenta tierras. Habitualmente aparecen limitadas por dos tierras $(62,70 \%)$; si sumamos todas aquéllas que solo están limitadas por otras tierras y ningún otro espacio agrario (bien sean tres, dos o una, haya tres o dos linderos, conozcamos éstos total o sólo parcialmente) nos situamos en el 93,65\%. Las tierras, por tanto, aparecen de modo casi exclusivo junto a otras tierras dentro de pagos cerealícolas. Se citan como linderos otros espacios agrarios, especialmente viñas, con o sin tierras, en un $4,76 \%$. Como en la mitad de estos casos se menciona también una tierra, debemos pensar que frecuentemente se trataría de parcelas situadas en una posición marginal dentro del terrazgo cerealícola y próximas a otros cultivos.

Las viñas presentan una situación similar. Conocemos los linderos total o parcialmente de ciento treinta y cuatro. Noventa y siete $(72,39 \%)$ están limitadas por dos viñas. Si sumamos todas las limitadas exclusivamente por viñas nos situamos en el 97,76\%; aparecen tierras con o sin otras viñas en el $2,24 \%$. En ningún caso una viña aparece rodeada por dos tierras; en todo caso, lindará con una viña y una tierra, o sólo con una tierra.

Tierras y viñas forman, por tanto, espacios compactos ${ }^{24}$. En las zonas marginales, podrían situarse colindantes, pero es algo raro. Seguramente entre los pagos cerealícolas y los vitícolas aparecerían espacios de separación que explicarían la bajísima proporción en que tierras y viñas se sitúan contiguas. Aunque no se alude a ellos en las ordenanzas de Galisteo, la elevadísima concentración de los diversos cultivos y su rígida separación necesitaría de los entrepanes o entrepastos, espacios incultos situados entre los pagos cultivados $^{25}$.

La situación no se presenta tan clara para aquellos espacios agrarios de menos peso, tales como huertos, alcáceres, linares u olivares. Su presencia en las fuentes que manejamos es muy escasa. No es infrecuente que estos espacios se concentren, al igual que sucede con las viñas, en una posición

\footnotetext{
${ }^{24} \mathrm{M}^{\mathrm{a}}$ del Carmen MARTín MARTín, El cabildo catedralicio de Plasencia en la Edad Media. Estudio social, económico y administrativo, Salamanca, 1999 (tesis doctoral inédita), p. 269, presenta una agrupacion menos rígida: una de cada cuatro viñas y la mitad de las huertas están rodeadas total o parcialmente por tierras de pan llevar, pese a la existencia de hojas cerealícolas y pagos vitícolas en Plasencia a finales de la Edad Media y comienzos de la Moderna (me baso para esto último en las ordenanzas de los siglos XV y XVI, transcritas y estudiadas, aunque aún inéditas, por el profesor Alfonso Rodríguez Grajera y por mí).

${ }^{25} \mathrm{Se}$ documentan estos espacios en las ordenanzas de Don Benito (Bibl. Complejo Cultural Santa Ana, Almendralejo) y Mengabril (AGS, Consejo Real, leg. 525, $\mathrm{n}^{\circ} 5$, a. 1549), ambas de 1549.

«Anuario de Estudios Medievales», 34/1 (2004), pp. 249-278.- ISSN 0066-5061.
} 
cercana a la población y junto a corrientes de agua. Estos aspectos, sin embargo, podemos poco más que intuirlos. Los huertos y huertas siempre aparecen juntos a otros huertos, siendo la disponibilidad de agua un factor que a veces se precisa ${ }^{26}$. Los dos linares que se mencionan están limitados por dos linares y por una tierra.

Tierras, viñas y huertos/as estarían agrupados, mientras que otros espacios agrarios de menor importancia se mezclarían con ellos. El terrazgo de Pozuelo se presenta organizado y estructurado, con una clara segregación entre espacios cercados y abiertos, aspecto sobre el que tenemos una información muy escasa ${ }^{27}$.

Las parcelas, independientemente de su dedicación, presentan una forma alargada ${ }^{28}$. Ese rasgo se ve con claridad, dentro de las zonas de más antigua ocupación, incluso en el parcelario actual. En ningún caso estamos ante campos rectangulares de trazado regular. Esta parcelario no ha surgido de ninguna planificación, sino probablemente de las divisiones hereditarias ${ }^{29}$. La forma alargada de las parcelas se percibe en la forma de delimitarlas. Habitualmente se presentan no cuatro lados, como es frecuente en otras zonas, sino sólo dos. Sobre trescientas treinta y dos parcelas, trescientas trece $(94,28 \%)$ se delimitan por dos lados y sólo diez $(0,30 \%)$ por tres. En algunos casos, aunque el número de linderos es superior a dos, la forma alargada es indudable y se precisa la existencia de sólo dos lados ${ }^{30}$.

La información sobre la extensión de las parcelas es muy reducida. No tenemos ninguna sobre las tierras de cereal. Muy reducida es también la

\footnotetext{
${ }^{26}$ No se indica la proximidad a corrientes de agua, sin embargo aparece "una huerta con naranjos e toronjos que alinda con la huerta del cura e de la otra parte con la fuente la Çarça" (fol. 326 v.); la iglesia de San Pedro de Pozuelo dispone de una huerta que cuenta con "una fuente que esta en la dicha huerta" (fol. $314 \mathrm{v}$.).

${ }^{27}$ Sobre esto Julián ClEMENTE RAMOS, Ordenanzas de Galisteo (1531), pp. 25-8.

${ }^{28}$ No parece una forma dominante en la España medieval, delimitándose las parcelas habitualmente por cuatro lados (José Angel GARCIA DE CORTAZAR, La sociedad rural en la España medieval, Madrid, 1988, p. 136).

${ }^{29} \mathrm{Marc}$ BLOCH, La historia rural francesa: caracteres originales, Barcelona, 1978, pp. 158-9.

30، una viña que ha por linderos de la una parte viña de Iohan de Chaves vesino de Galisteo e de la otra parte la de Juan Apariçio e otros çiertos linderos" (fol. 320 r.); "otra tierra en Valdenovas que alinda con tierra de Juan Rs. e de la otra parte con tierra de Alfons Sanches e otros çiertos linderos" (fol. 324 r.); "otra tierra al Teso de Juan Blanco que alinda con el dicho Juan Blanco e de la otra parte con tierra de Martin Rodriguez e otros çiertos linderos" (fol. 327 r.).

«Anuario de Estudios Medievales», 34/1 (2004), pp. 249-278.- ISSN 0066-5061.
} 
disponible sobre las viñas ${ }^{31}$. Es posible acercarnos a este aspecto de una forma indirecta cruzando los datos sobre extensión y número de parcelas de algunas explotaciones. De este modo, podemos hallar la extensión media de las parcelas de cada explotación y, cuando el propietario en cuestión sólo disponga de una viña y/o una tierra, también la extensión de algunas de ellas. Se trata en todo caso de una información limitada, pero que nos permitirá abordar esta característica del parcelario.

La extensión media de las parcelas de cereal se sitúa en 4,04 fanegas. Esta media puede considerarse representativa pues ha sido obtenida sobre ciento veintitrés parcelas de cuarenta propietarios ${ }^{32}$. La extensión media de las parcelas de estas explotaciones (en fanegas) sería la siguiente:

\begin{tabular}{|c|c|c|c|c|c||}
\hline $1-<2$ & $2-<3$ & $3-<4$ & $4-<5$ & $5-<6$ & $\geq 6$ \\
\hline 6 & 9 & 7 & 6 & 1 & - \\
\hline
\end{tabular}

Estamos hablando, en todo caso, de la extensión media de las parcelas en cada explotación y no propiamente de la extensión de las parcelas. Diez propietarios sólo disponen de una tierra ${ }^{33}$ y por ello su extensión es igual a toda la propiedad disponible. La extensión de estas parcelas es la siguiente:

\begin{tabular}{|c|c|c|c|c|c|}
\hline $1-<2$ & $2-<3$ & $3-<4$ & $4-<5$ & $5-<6$ & $\geq 6$ \\
\hline 2 & 1 & 2 & 1 & - & 4 \\
\hline
\end{tabular}

La extensión media de las parcelas de las distintas explotaciones presenta una menor diversidad que su extensión real. Se trata, en todo caso, de un muestreo muy limitado, pero cuyas características parecen razonables. Las parcelas de cereal se dividírían, con un peso quizás bastante similar, en

\footnotetext{
31 "una viña de tres quartas que conpro de los herederos de su padre, e otra quarta que conpro de Garrovillano" (fol. 279 v.).

${ }^{32}$ Es una media elevada: en Haro oscilaban normalmente entre una y tres fanegas (Francisco Javier GoICOLEA JULIÁN, Haro: una villa riojana del linaje Velasco a fines del Medievo, Logroño, 1999, pp. 84-5) y en Burgos la parcela modal es de 2,87 fanegas (Hilario CASADO ALONSO, Señores, mercaderes y campesinos. La comarca de Burgos a fines de la Edad Media, Madrid, 1987, pp. 148-9).

${ }^{33} \mathrm{Sin}$ contar a Pedro Manzano, que posee una tierra, pero que en la lista de propietarios sólo aparece como propietario de viñas (fols. 282 v. y 327 v.).

"Anuario de Estudios Medievales», 34/1 (2004), pp. 249-278.- ISSN 0066-5061.
} 
pequeñas (menos de tres fanegas y sobre todo menos de dos), medianas (entre tres y cinco fanegas) y grandes (más de seis fanegas).

La información sobre las viñas es tambien muy limitada. Su extensión media se sitúa en 0,81 cuartas. Este índice se obtiene de ciento una parcelas de cuarenta y seis propietarios que totalizan 81,75 cuartas. La extensión media de las viñas de estas explotaciones (en cuartas) es la siguiente:

\begin{tabular}{|c|c|c|c|c|c|c|}
\hline$<0,25$ & $0,25-0,49$ & $0,5-0,99$ & $1-1,49$ & $1,5-1,99$ & $2-2,99$ & $\geq 3$ \\
\hline 1 & 6 & 14 & 15 & 4 & 4 & - \\
\hline
\end{tabular}

Conocemos la extensión de seis viñas, que alcanzan 0,5 , una (tres), tres y cinco cuartas. Por otro lado, dieciseis propietarios sólo cuentan con una viña y conocemos la extensión que poseen de este cultivo. La extensión de todas estas viñas es la siguiente:

\begin{tabular}{|c|c|c|c|c|c|c|}
\hline$<0,25$ & $0,25-0,49$ & $0,5-0,99$ & $1-1,49$ & $1,5-1,99$ & $2-2,99$ & 23 \\
\hline- & 1 & 5 & 10 & 2 & 2 & 2 \\
\hline
\end{tabular}

La extensión de las viñas se sitúa entre media cuarta y una y media. Son raras las de menor extensión y no abundan las mayores.

Tierras de cereal y espacios cercados presentan diferentes característica físicas. Apenas tenemos información sobre las tierras cerealícolas. Éstas se presentan como campos abiertos y ofrecen pocos rasgos resaltables. Pueden tener olivos, pero no sería algo habitual ${ }^{34}$. Una tierra dispone de fuente, aunque no sabemos si se utilizaba para el riego ${ }^{35}$. No aparecen en estas parcelas encinas u otras quercíneas. Esto no es meramente casual, pues se alude de modo general, como luego veremos, a la existencia de arboles en las viñas. Todo nos lleva a pensar que los espacios cerealícolas han sufrido una roturación total y no cuentan con arbolado alguno, son espacios calvos.

Frente a las tierras, viñas, huertas y espacios cercados en general ofrecen una realidad más compleja, al ser base de un policultivo con

\footnotetext{
${ }^{34} \mathrm{El}$ que se mencione dos veces que una tierra tenga seis olivos parece confirmar la rareza de esta situación (fols. 286 r. y 331 v.).

35 "siete hanegadas de tierras con una fuente que se dise de Retuerta" (fol. 280 r.).

«Anuario de Estudios Medievales», 34/1 (2004), pp. 249-278.- ISSN 0066-5061.
} 
características precisas. Sólo excepcionalmente se alude al carácter cercado de estos espacios ${ }^{36}$. No podemos, sin embargo, dudar de esta característica ${ }^{37}$. En la tasación de los daños producidos por los vecinos de El Campo y otros lugares de la tierra de Santibáñez, se indica que "cada viña va estimada con sus arboles" (fol. 271v). Dentro de ellas se desarrolla la fruticultura. Sin duda, abundan las higueras y los olivos, tan importantes en la producción rural de Pozuelo. Aparecen viñas con un número limitado de higueras, entre una y $\operatorname{tres}^{38}$. Posiblemente, esta situación estaría muy generalizada, pues la higuera es, y no sólo en Pozuelo, el árbol de fruto que alcanza una mayor difusión en el mundo rural extremeño de la baja Edad Media. De otro modo, además, no se puede explicar que la producción de higos sea tan elevada. La asociación vid-higuera debió estar, por tanto, muy difundida. La asociación vid-olivo se precisa también en alguna ocasión ${ }^{39}$, aunque aparece más frecuentemente de modo implícito. Cuando se enumeran las destrucciones, se alude a veces conjuntamente a daños producidos en viñas y olivares ${ }^{40}$. Esto nos hace pensar en la proximidad de ambos cultivos, que posiblemente estarían integrados dentro de las propias viñas. La asociación vid-olivo no sería menos importante que la anterior. Incluso, sería muy posible que las viñas contarán tanto con higueras como con olivos, algo que la limitada información sobre estos cultivos complementarios no permite documentar. Todo nos hace pensar que, dada la gran difusión del viñedo y la práctica del policultivo en las viñas, éstas albergarían una parte mayoritaria de la producción de higos y aceite.

Los árboles frutales también proliferan en los huertos. Esta actividad parece presentar en estos mayor diversidad que en las viñas, diversidad que no captamos en toda su amplitud por la limitada presencia que el cultivo hortense tiene en la fuente que manejamos. No se alude en ningún caso a la existencia de higueras en huertos/as, quizás debido a su menor frecuencia. Sin

\footnotetext{
36 "vieron un çerrado de Juan de la Çarça e viña e oliveras e otros arboles e su çerradura.." (fol. 271 v.) "vido destruir otras viñas e açernadar oliveras e poner fuego a la çerradura e barda del majuelo de Juan de la Çarça (n $7-2$, fol. 119 v.).

${ }^{37}$ Julián Clemente RAMOS, Ordenanzas de Galisteo (1531), pp. 27.

38 "una quarta de viña con dos figueras" (fol. 285 r.); "seys quartas con tres figueras" (fol. 285 v.); "vido cortados veynte e dos pies de olivos contados e que a este testigo una higuera que tenia ge la cortaron syn el daño de las vides e çepas" ( $\mathrm{n}^{0} 7-2$, fol. $121 \mathrm{v}$.).

39 "otra viñas oliveras de Pedro Halcon" (fol. 268 r.).

${ }^{40} \mathrm{Cf}$. notas 32 y 34 ; igualmente: "vieron un çerrado de Juan de la Çarça e viña e oliveras e otros arboles e su çerradura.." (fol. 271 v.).

«Anuario de Estudios Medievales», 34/1 (2004), pp. 249-278.- ISSN 0066-5061.
} 
embargo, si fue habitual el cultivo del olivo, que pudo llegar a constituir una parte muy importante de la producción y ser el único arbol cultivado ${ }^{41}$. Aparecen también otros árboles con menos peso como los cítricos (naranjas, limas, toronjas ${ }^{42}$.

El cultivo del olivo se desarrolla en los olivares y, como hemos indicado, en viñas y huertos. En todo caso, estamos ante un cultivo con poco desarrollo que aún no ha adquirido una importancia central en las economías de montaña ${ }^{43}$. Esta realidad seguía vigente para la tierra de Galisteo algunas décadas más tarde ${ }^{44}$. Los olivares como tales serían poco numerosos. En el listado de propietarios presentados por Diego de la Torre, aparecen las siguientes menciones sobre el cultivo del olivo:

\begin{tabular}{|c|c|c|c|}
\hline Olivares & Huertos con olivos & Tierra con olivos & $\begin{array}{c}\mathrm{N}^{\circ} \text { determ. de } \\
\text { olivos }\end{array}$ \\
\hline 4 & 2 & 1 & 6 \\
\hline
\end{tabular}

A estos datos debemos añadir el desarrollo que este cultivo encontró en las viñas. Por otro lado, el número de huertos/as que aparece en la fuente que utilizamos creemos que es muy limitado, lo que afecta a la valoración que podamos hacer del cultivo oleícola. En algunos casos se menciona, como hemos visto, un número determinado de olivos sin precisar en que tipo de espacio se ubican. Se trata de un cantidad limitada que oscila entre uno y ocho. Aparece un terreno con veintitrés olivos que parece constituir un

${ }^{41}$ "un huerto de oliveras conprado" (fol. 85 r.); "E mas un huerto con oliveras que heredo" (fol. $286 \mathrm{r}$.).

42 "una huerta con unos limos" (282 r.); "una huerta con naranjos e toronjos que alinda con la huerta del cura" (326 v.).

${ }^{43} \mathrm{~A}$ finales de la Edad Media, este cultivo tiene un escaso desarrollo en Extremadura: Daniel RodRíGUEZ BLANCO, La Orden de Santiago en Extremadura en la Baja Edad Media (siglos XIV $y X V$ ), Badajoz, 1985, p. 246. Sin duda, en las zonas de montaña está iniciándose un desarrollo de este cultivo, como parece señalar el caso de Gata (Alonso de TORRES Y TAPIA, Cronica de la Orden de Alcántara, Madrid, 1763, II, p. 514, a. 1486) o Torre de Don Miguel (Ibíd., p. 531, a. 1488); a principios del siglo XVI, Jarandilla de la Vera dispone de "muchos prados e castañares e robledos e heredades, guertos e olivares e viñas e otros muchos heredamientos" (AHN, Frías, leg. 1369, $\mathrm{n}^{\circ} 8$, fol. $58 \mathrm{v}$.); Andalucía cuenta con comarcas, como el Aljarafe, con un gran desarrollo oleícola (Mercedes BORRERO FERNÁNDEZ, El mundo rural sevillano en el siglo $X V$, p. 117; Isabel MONTES ROMERO-CAMACHO, El paisaje rural sevillana en la baja Edad Media, Sevilla, 1989, cuadro p. 247).

${ }^{44}$ Julián Clemente Ramos, Ordenanzas de Galisteo (1531), pp. 31-2.

«Anuario de Estudios Medievales», 34/1 (2004), pp. 249-278.- ISSN 0066-5061. 
olivar $^{45}$. Todo nos hace pensar que al cultivo del olivo se dedicarían espacios de extensión limitada. Se trata de un cultivo que solo empieza a adquirir importancia en zonas de montaña o en zonas que, como Pozuelo, presentan una realidad económica que se ajusta parcialmente a estas pautas.

\section{CONCLUSIÓN}

La estructura agraria de Pozuelo se presenta, como hemos visto, con una gran claridad y precisión en el conflicto que enfrenta a esta comunidad con El Campo. Aldea situada en la base de los relieves montañosos del Sistema Central, desarrolla una economía que sin ser estrictamente de montaña presenta mucha de sus características. Junto al cultivo cerealícola, que ocupa la mayor parte del terrazgo agrario, la producción vinícola adquiere una importancia fundamental. Junto a ella, otras producciones que se obtienen de esos espacios limitados en extensión que constituyen los terrenos cercados (higos, aceite, sin duda también hortalizas) configuran una economía rural equilibrada y polivalente. El valor conjunto de las producciones de vino, aceite, fruta y hortaliza debió estar muy próximo al del cereal. Este modelo agrario se opone con claridad al dominio cerealícola de muchas zonas de llanura.

Esta actividad económica se da dentro de un espacio que presenta un parcelario maduro. Así interpretamos el predominio de las parcelas rectangulares alargadas, opuestas a las cuadradas, más abundantes en fases iniciales de ocupación. Las primeras no surgen de ninguna planificación inicial del tipo de las existentes en algunas zonas del norte de Europa. El dominio en la actualidad de un parcelario abigarrado e irregular, que rompe continuamente la línea recta, nos impide pensar en un origen de este tipo. Posiblemente las divisiones hereditarias han modelado el parcelario. Este dominio de parcelas alargadas se da junto a una concentración rigurosa de los pagos cerealícolas, no divididos en hojas, y vitícolas. Posiblemente, entre ambos cultivos hay espacios de separación que explican la casi total ausencia de viñas y tierras colindantes.

45 "veynte y tres pies de oliveras con su terreno" (fol. 285 r.).

«Anuario de Estudios Medievales», 34/1 (2004), pp. 249-278.- ISSN 0066-5061. 
La propiedad agraria de tipo cerealícola se presenta muy desigualmente repartida. Constituyen una minoría aquéllos que poseen una explotación media y son muy pocos los que podemos considerar acomodados. Controlan, sin embargo, una gran parte de la propiedad. En la base, aparece un gran número de pequeños propietarios y de no propietarios. Esta situación desequilibrada tiene un contrapeso en la propiedad vitícola. Los que tienen poca o ninguna tierra de cereal acumulan, junto a los no residentes, la mayor parte del viñedo. Asimismo, debido a su actividad compradora, están incrementando su participacion en este cultivo. Sin duda, las viñas, que tienen una gran importancia económica pese a su reducida peso en el conjunto del terrazgo agrario, son espacios de una elevada productividad en los que, además de vino, se obtienen también aceite e higos. Sin duda, la propiedad vitícola es el mayor recurso de los campesinos humildes. Todo esto nos hace pensar en un cierto equilibrio social. Sin duda, esta circunstancia está vinculada a la elevada productividad de las viñas, algo que ante la ausencia de datos cuantitativos sólo podemos intuir. 


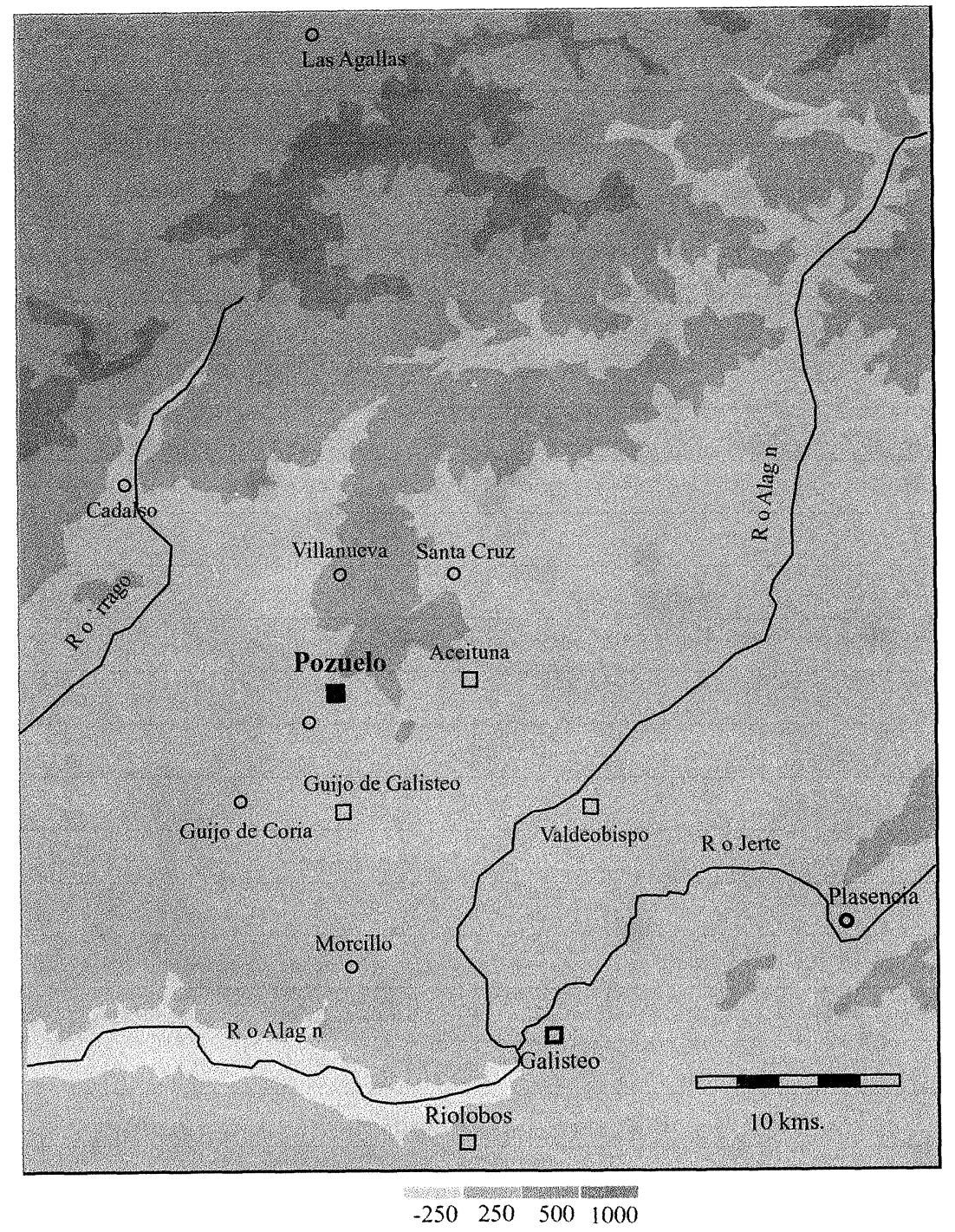

Mapa 1: La propiedad no vecinal en Pozuelo (1498)

口 Poblaci n de la Tierra de Galisteo ( $1-4 / 5$ o mas propiedades)

○ Otras poblaciones (id.) 


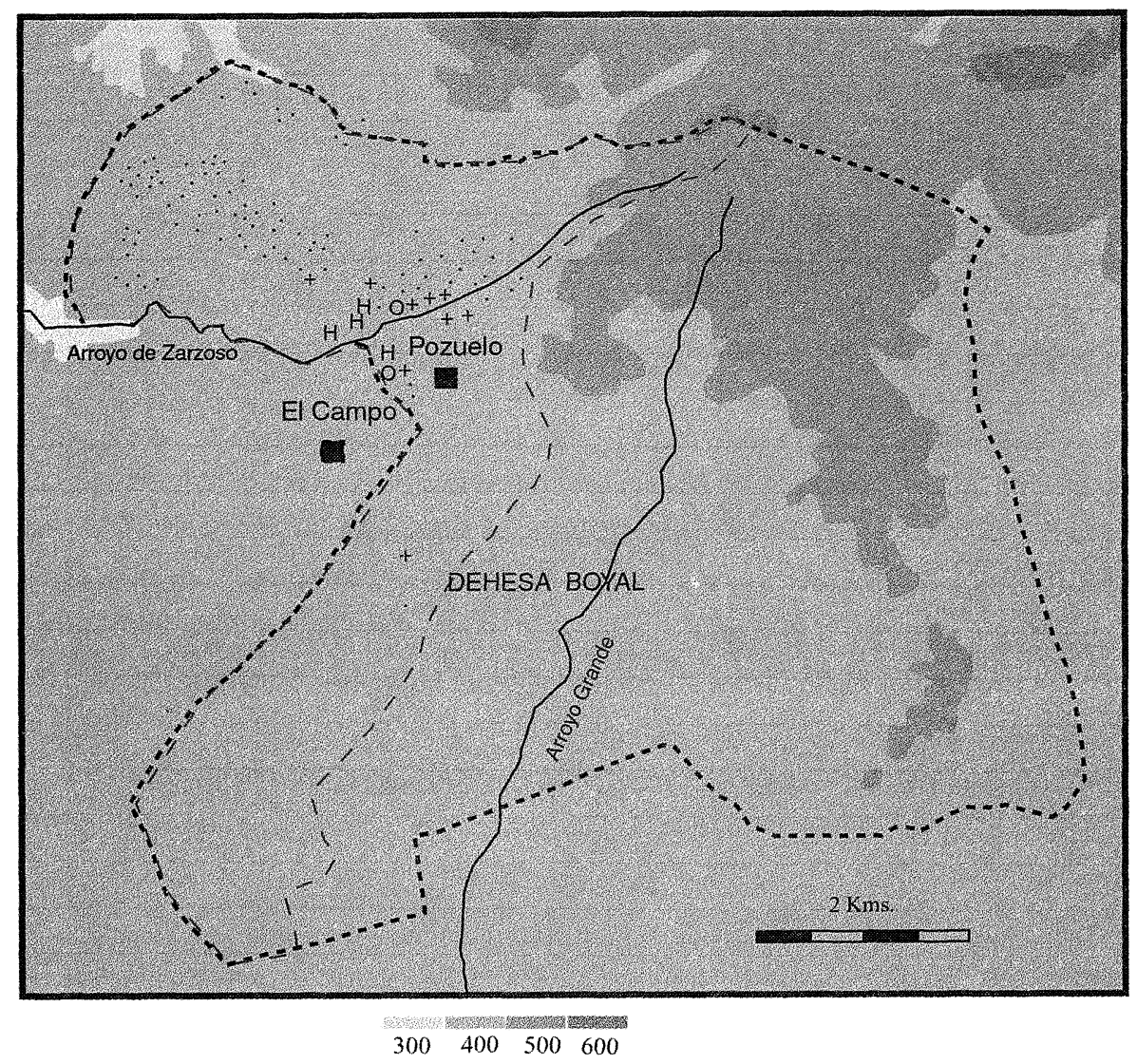

Mapa 2: El terrazgo agrario de Pozuelo (1498)

$\begin{array}{cc} & \text { Poblaci n } \\ + & \text { Tierra } \\ + & \text { Viaa }\end{array}$
O Olivar
H Huerto/a
- Predominio del parcel. alargado en la actualidad 